\title{
PROJECT SPENS - SUSTAINABLE PAVEMENT FOR EUROPEAN NEW MEMBER STATES
}

This paper represents the main results of work package 5 of the SPENS project (Sustainable Pavements for European New Member States) that was focused on assessment of the impact of roads on the environment and where the Faculty of Civil Engineering of University of Zilina was the most active and closely cooperated with CDV.

Collaborative international project was focused on particulate matter (PM) production due to mechanical abrasion of road pavements. $P M$ (and noise emission) was captured next to roads with different pavement types (stone mastic asphalt and asphalt concrete) by middle volume samplers with consequent gravimetric analysis of each exposed filter. The content of organic and inorganic pollutants fixed to PM was determined to characterise the PM composition. Dust fall measurements including mass and chemical composition determination in road tunnels with different pavements (cement concrete and asphalt concrete) were done to determine the pavement abrasion contribution to overall PM emissions in tunnels.

Keywords: Roads, traffic volume, environment, particulate matter/PM/, traffic noise.

\section{Project introduction}

The Faculty of Civil Engineering, University of Zilina, Department of Highway Engineering was involved in solution of the Project SPENS - Sustainable Pavements for European New Member States supported by the Sixth Framework Programme within priority 1.6.2 Sustainable Surface Transport. The objective of the SPENS research project was to develop appropriate tools and procedures for the rapid rehabilitation of road pavements especially in the EU new member states using materials and methods that would behave satisfactorily in a typical climate, have an acceptable environmental impact, be easy to incorporate within existing technologies and be cost-effective and easy to maintain. In the period of September 2006 to August 2009 partners including VTI Sweden, CDV Czech Republic, ZAG Slovenia, Arsenal Austria, KTI Hungary, IBDiM Poland, DDC Consulting \& Engineering Ltd. Slovenia, Ferriere nord S.p.A. Italy, FEHRL Belgium cooperated in the performance of laboratory and field tests of asphalt materials, as well as in the evaluation of the impact of roads on the environment. The research work was organized into four technical work packages (WP).

\section{State of the art}

Air pollution related to transportation is one of the most discussed issues within the context of negative impacts on the environment at present. Combustion processes are the reason of exhaust gas emissions that contain hundreds of chemical compounds in different concentrations contributing to the greenhouse effect and often with toxic, carcinogenic or mutagenic effects on organisms including humans [1], [2]. Particularly PAHs and POPs belong to the most dangerous ones that originate due to fuel combustion [3]. However, pollutant emissions, especially particulate matter (PM), could be also related to non-combustion processes such as resuspension or mechanical abrasion of particles during the interaction between tires and road pavement. Mechanically separated particles from the pavement (asphalt particles, soil dust etc.) especially on damaged roads, abrasion of tyres and brake-shoe lining, particles of chemical (mineral salt) and inert (gravel, sand, slag) materials for road maintenance in winter season and carried materials falling off are the significant sources of overall PM air pollution [4], [5]. All of these particles quickly settle on road surface near their sources due to their size and get again into the air due to turbulent flow initiated by vehicle movement and wind blow. Resuspension due to road transport contributes particularly to an increase of total suspended particles (TSP) and $\mathrm{PM}_{10}$ fraction [6] and depends on specific local conditions such as road surface, vehicle speed and weight and air humidity. Resuspended dust is hazardous due to its enrichment by risk compounds that are emitted by other anthropogenic sources [7], [8], [9]. Inorganic particles are generated mostly due to abrasion of cement concrete pavement [10]. These particles also represent $90 \%$ of particles from asphalt pavement abrasion [11]. It is assumed that aggregates generated due to wear of road pavement are composed mostly of $\mathrm{Al}, \mathrm{Si}, \mathrm{Ca}, \mathrm{Mg}$, $\mathrm{C}$ and $\mathrm{Na}$, or $\mathrm{K}$ in the forms of their oxides. Other metals represent other sources such as mechanical abrasion of car bodies and vehicle other parts $(\mathrm{Cu}, \mathrm{Sn}, \mathrm{Cr}, \mathrm{Pb}, \mathrm{Cd}, \mathrm{As}, \mathrm{Sb})$, mechanical abrasion of brake shoe lining $(\mathrm{Cu}, \mathrm{Sb}, \mathrm{Ba})[12]$ and catalytic converters (Pt. Pa, Rh) [13].

\footnotetext{
* Daniela Durcanska ${ }^{1}$, Martin Decky ${ }^{1}$, Roman Licbinsky ${ }^{2}$, Jiri Huzlik ${ }^{2}$

${ }^{1}$ Faculty of Civil Engineering, University of Zilina, Slovakia, E-mail: daniela.durcanska@fstav.uniza.sk

${ }^{2}$ Division of Transport Infrastructure and Environment, Transport Research Centre, Brno, Czech Republic
} 
Increasing traffic volumes on the European road network are directly related to increasing annoyance of the population due to noise, which is a huge problem throughout the EU. To achieve road traffic noise abatement not only with passive measures, like noise barriers, but by reducing noise emissions at the source, it is necessary to assess the influence of pavements on the noise emission process and to make use of low-noise pavements. The paper describes results of measurements carried out according to the method of comparing traffic noise on different road surfaces for various compositions of road traffic for the purpose of evaluating different road surface types.

\section{Methods}

\subsection{PM and dust fall sampling and analyses}

Two methods were chosen to evaluate the contribution of road pavement abrasion to air pollution by particulate matter - active PM sampling on common localities and passive measurements of dust fall in road tunnels. It is assumed that contribution of PM from non traffic sources is insignificant comparing with emissions from traffic in tunnels.

PM were captured on different filter types using middle volume samplers LECKEL MVS6 (Sven Leckel Ingenierbüro, Germany) with consequent gravimetric analysis on Mettler-Toledo MX5/A microbalance (Mettler-Toledo GmbH, Switzerland) of each exposed filter to determine PM concentrations. Two localities in Zilina city area, Slovakia next to roads with different types of pavements were chosen. D1 highway in Predmier with traffic intensity of 28,000 vehicles per 24 hours with Stone Mastic Asphalt SMA represents the first one and urban through-road I/18 in Zilina - Mostna Street with traffic intensity of 25,000 vehicles per 24 hours with Asphalt Concrete AC was the second one.
Dust fall measurements were realized in road tunnels with different pavements that are the components of Prague city ring, Czech Republic. Mrazovka tunnel with traffic intensity of 42,400 vehicles per 24 hours with Asphalt Concrete (AC) road pavement and Strahovsky tunnel with traffic intensity of 44,500 vehicles per 24 hours with cement concrete (CC) road pavement. Sampling devices for dust fall measurements were placed near the tunnel centre, 4 sedimentation glasses in each tunnel tube with the neck diameter of $90-200 \mathrm{~mm}$ and high $145-400 \mathrm{~mm}$ filled with the mixture of $250 \mathrm{ml}$ distilled water and $25 \mathrm{ml}$ izopropanol. Sampling interval was 28 days due to regular tunnel cleaning procedure. Captured sample of dust fall was for determination of overall content of inorganic compounds burned in $710{ }^{\circ} \mathrm{C}$ [9]. Partial pressure of $\mathrm{CO}_{2}$ above $\mathrm{CaCO}_{3}$ is in this temperature approximately $4 \mathrm{kPa}$ and $\mathrm{CaCO}_{3}$ is not significantly decomposed in this temperature. Chemical composition of burned residuum thus represents aggregates used in road pavement.

Subsequent chemical analyses were proceeded to determine the content of selected metals using inductively coupled plasma mass spectrometry (Thermo Scientific X series 2, Thermo Electron Limited, United Kingdom) and polyaromatic hydrocarbons (PAH) using gas chromatography-mass spectrometry (Shimadzu QP2010, Japan) and to find out the differences in composition of PM originated due to vehicles operation on roads with different pavements.

\subsection{Measurement of the influence of road surfaces on traffic noise.}

Traffic noise measurements were performed by using Statistical Pass-By-Method (SPB) that is described in the ISO 11819-1 standard [14]. It provides a method to determine an index which can be used to compare the noise emission impact of different road

\begin{tabular}{|l|l|l|l|}
\hline \multicolumn{1}{|c|}{ Category } & $\begin{array}{l}\text { 2 axles, } \\
4 \text { wheels } \\
\text { Passenger cars }\end{array}$ & Minimum number of pass-bys \\
\hline 1) cars & $\begin{array}{l}2 \text { axles, more than 4 wheels } \\
\text { Light trucks, buses }\end{array}$ & $30(2 \mathrm{a}+2 \mathrm{~b}=80)$ \\
\hline 2a) dual-axle heavy vehicles & $\begin{array}{l}\text { Heavy trucks } \\
\text { More than 2 axles }\end{array}$ & & $30(2 \mathrm{a}+2 \mathrm{~b}=80)$ \\
\hline 2b) multi-axle heavy vehicles & & \\
\hline
\end{tabular}


surfaces by measuring vehicle pass-bys at the roadside. The SPB method is based on the measurement of the maximum A-weighted sound pressure levels of a statistically significant number of individual vehicle pass-bys (Table 1) together with the vehicle speeds. Specific measurements of A sound levels LA were conducted by a sound analyser NOR-121 (Norsonic, Norway - ID 31211) accuracy Class 0 . The sound analyser was prior to each set of measurements calibrated by a microphone calibrator NOR N-1251 (Norsonic, Norway - ID 31069), accuracy Class 1. Applied measuring string of noise emissions and pollution had separate verification for own sound level meter, measuring microphone Nor-1225 (Norsonic, Norway - ID 48045), one-third-octave filters, acoustic calibrator. Velocity measurements were realised by a speed radar gun Bushnell Speedster (Table 1) and meteorology conditions by a Wireless weather station - WS 888 set (Table 1).

The passing vehicles were classified into one of three vehicle categories and one of three reference speeds was chosen according to the average operating speed of the road (Table 2).

A regression line of the maximal A-weighted sound pressure level versus the logarithm of speed was calculated for the pass-bys of every category (Fig. 1).
This regression line was then used to determine the average maximum A-weighted sound pressure level $L_{v e h}$ at the reference speed. The $L_{v e h}$ of the three vehicle categories $\left(L_{\text {veh, }, 1, \text { regression }} \equiv L_{1}\right.$, $\left.L_{v e h, 2 a, \text { regression }} \equiv L_{2 a}, L_{v e h, 2 b, r e g r e s s i o n} \equiv{ }_{L 2 b}\right)$ can be combined to give a single index called SPBI (Statistical Pass-By Index) which is indicative of the influence of the road surface on the noise emission of a mixed vehicle collective.

$$
\begin{aligned}
& S P B I=10 \cdot \log \left[W_{1} \cdot 10 \frac{L_{1}}{10}+W_{2 a} \cdot\left(\frac{v_{1}}{v_{2 a}}\right) .\right. \\
& \left.\cdot 10 \frac{L_{2 a}}{10}+W_{2 b} \cdot\left(\frac{v_{1}}{v_{2 b}}\right) \cdot 10 \frac{L_{2 b}}{10}\right]
\end{aligned}
$$

where:

SPBI - the Statistical Pass-by Index, for a standard mix of light and heavy vehicles

$L_{1}, L_{2 \mathrm{a}}, L_{2 \mathrm{~b}} \quad$ - the Vehicles Sound Levels for vehicle categories 1, 2a, 2b (Fig. 1),

$W_{1}, W_{2 a}, W_{2 b}$ - the weighting factors which are equivalent to the assumed proportions of vehicle categories in the traffic (Table 2)

$v_{1}, v_{2 a}, v_{2 b} \quad$ - the reference speeds of individual vehicle categories (Table 2).

\begin{tabular}{|c|c|c|c|c|c|c|c|}
\hline \multirow{2}{*}{\multicolumn{2}{|c|}{ Vehicle category }} & \multicolumn{6}{|c|}{ Road speed category } \\
\hline & & \multicolumn{2}{|c|}{ Low } & \multicolumn{2}{|c|}{ Medium } & \multicolumn{2}{|c|}{ High } \\
\hline Name & No. & Ref. speed [kph] & $W_{x}$ & Ref. speed [kph] & $W_{x}$ & Ref. speed [kph] & $W_{x}$ \\
\hline Cars & 1 & 50 & 0.900 & 80 & 0.800 & 110 & 0.700 \\
\hline Dual-axle heavy vehicles & $2 \mathrm{a}$ & 50 & 0.075 & 70 & 0.100 & 85 & 0.075 \\
\hline Multi-axle heavy vehicles & $2 b$ & 50 & 0.025 & 70 & 0.100 & 85 & 0.225 \\
\hline
\end{tabular}
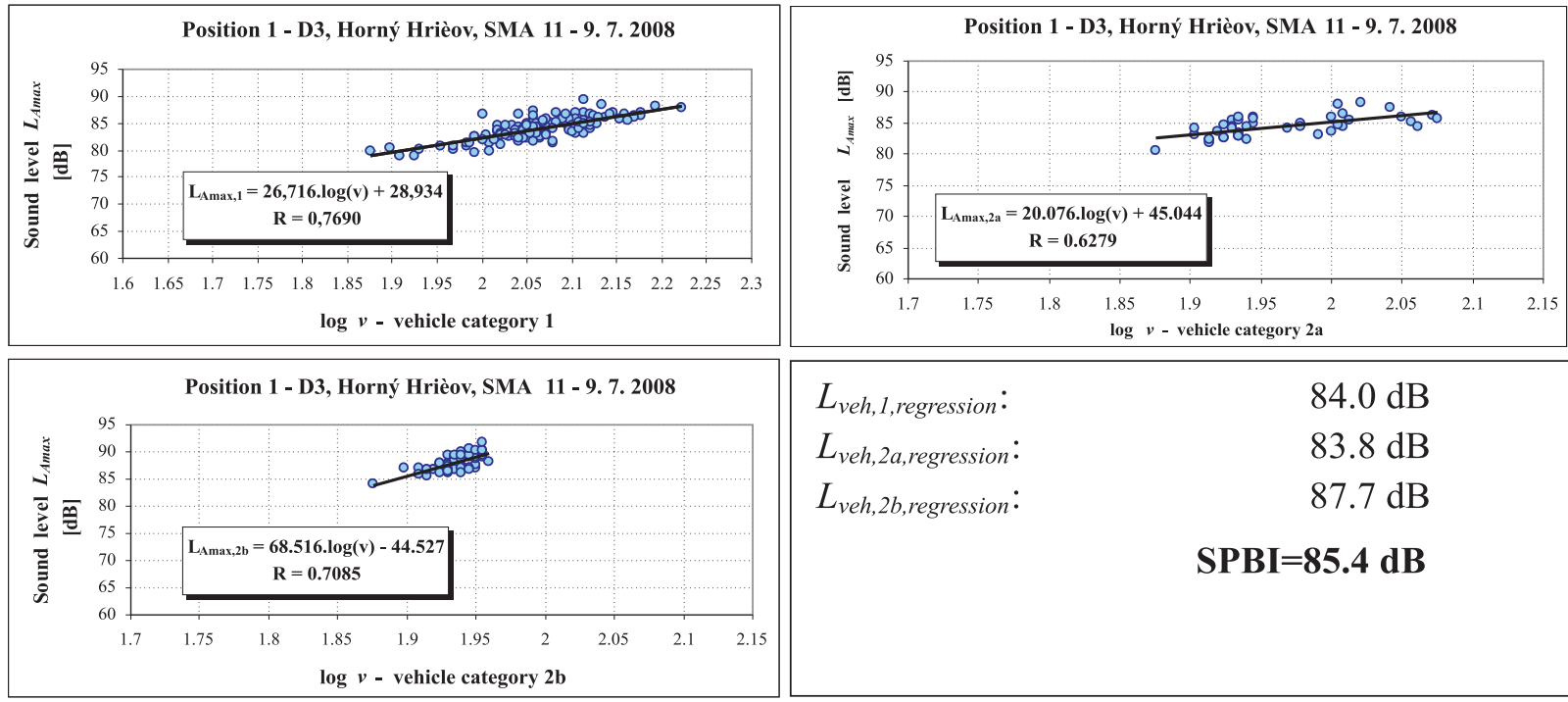
$L_{\text {veh, } 1, \text { regression }}:$
$84.0 \mathrm{~dB}$
$L_{\text {veh,2a, regression: }}$
$83.8 \mathrm{~dB}$
$L_{v e h, 2 b, \text { regression: }}$
$87.7 \mathrm{~dB}$

$\mathrm{SPBI}=85.4 \mathrm{~dB}$

Fig. 1 Regression lines for Position 1 


\section{Results and discussion}

\subsection{PM and dust fall measurements}

It is assumed that inorganic particles originated by abrasion of cement-concrete pavements consist mostly of coarse PM fraction. The share of this coarse fraction on total $\mathrm{PM}_{10}$ concentrations was higher at sites with asphalt concrete (AC) surface at the city ring (approximately $48 \%$ ) than its share in stone mastic asphalt (SMA) - 35 to $40 \%$. This was confirmed during both sampling campaigns (Fig. 2). $\mathrm{PM}_{1.0}$ fraction was generally predominant in both campaigns at both sites that indicate the origin of more particles due to combustion processes. These results also indicate higher production of coarse PM fraction due to abrasion of asphalt concrete.

Chemical composition of captured PM separate fractions was analysed. Content of selected elements representing sources related to mechanical abrasion of particles, such as $\mathrm{Zn}, \mathrm{Sb}, \mathrm{Cu}, \mathrm{Ba}$ and others, were determined in both coarse and fine PM fractions.

Elements concentrations were higher in both PM fractions at sites with $\mathrm{AC}$ pavement in both sampling campaigns, except $\mathrm{K}$ and $\mathrm{Pb}$ in the second measuring period in autumn. Elemental composition of $\mathrm{PM}_{10}$ fraction in summer sampling campaign is shown in Fig. 3 and indicates higher production of PM due to abrasion of $\mathrm{AC}$ pavement ( $\mathrm{Ca}, \mathrm{Mg}$ content) or due to abrasion of tyres $(\mathrm{Zn}$ content) during the interaction with $\mathrm{AC}$ pavement.

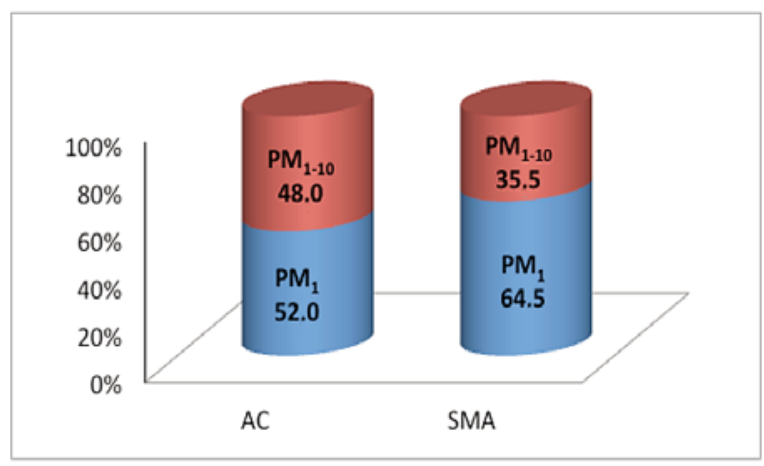

Fig. 2 The share of PM fractions (summer and autumn sampling campaign)
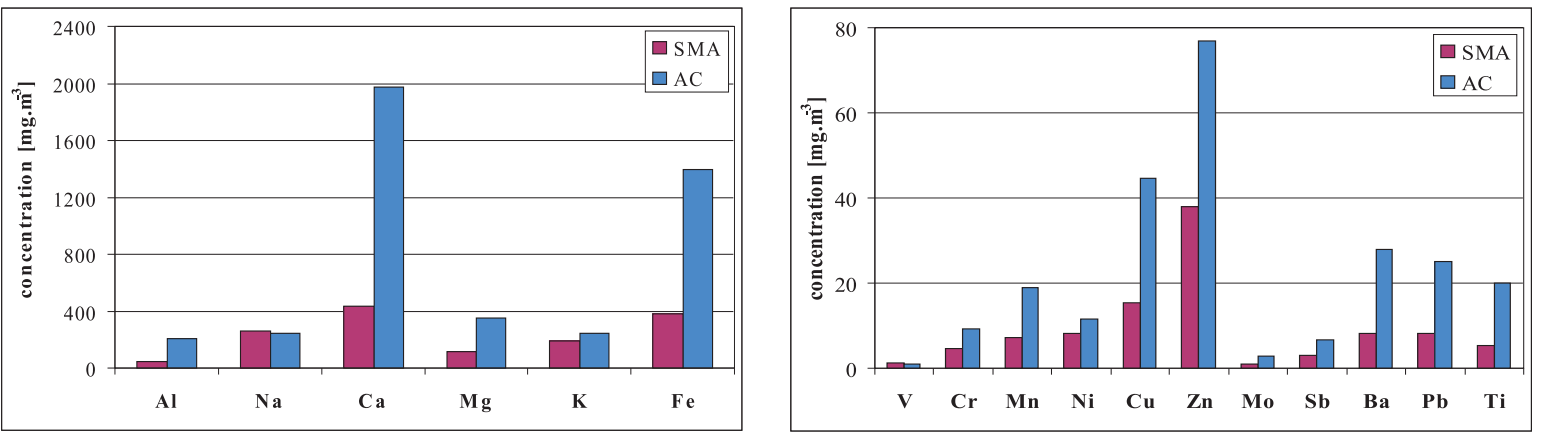

Fig. 3 Content of selected elements in summer sampling campaign-macro components in the left graph, micro components in the right graph

$\mathrm{PM}_{2.5}$ fraction was also measured and content of Polyaromatic Hydrocarbons (PAH) was determined (see Fig. 4). 18 PAH were analysed in accordance with US EPA list of importance including Benzo[a]pyrene and Dibenz[a,h]anthracene as the most harmful compounds and Coronene as the fuel combustion in vehicles engines indicator. Higher PAH concentrations were determined during the autumn sampling campaign on both localities but there were found no statistically significant differences between localities. So small amount of PAH during the summer campaign could be caused by the PAH occurrence mostly in the gaseous phase due to higher temperatures.

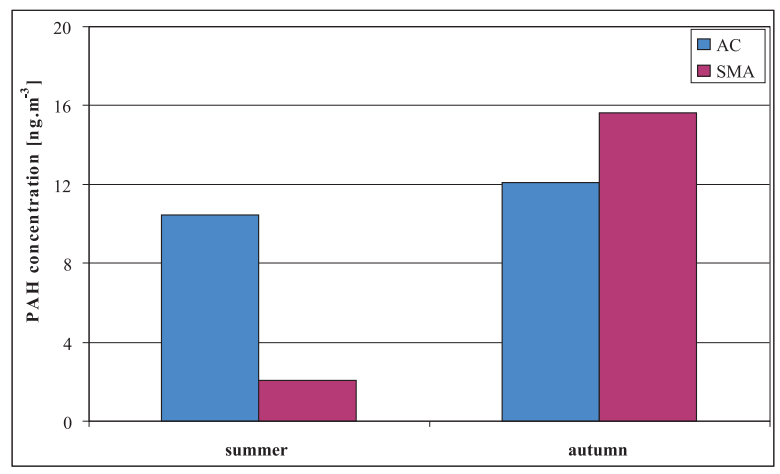

Fig. 4 PAH content in $P M_{2.5}$ fraction

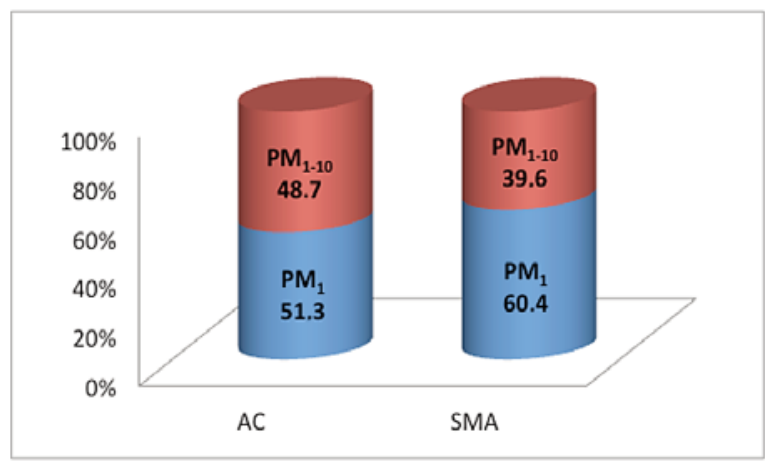




\begin{tabular}{|c|c|c|c|c|c|c|c|c|}
\hline \multirow[t]{2}{*}{ Tunnel } & \multirow[t]{2}{*}{ Pavement } & \multirow[t]{2}{*}{ Slope } & $\begin{array}{l}\text { Dust fall inor- } \\
\text { ganic share }\end{array}$ & $\begin{array}{c}\text { Dust fall } \\
\text { organic share }\end{array}$ & Dust fall total & PAH summ & $\begin{array}{c}\text { Dust fall } \\
\text { organic share }\end{array}$ & $\begin{array}{l}\text { PAH share } \\
\text { from organic } \\
\text { dust fall }\end{array}$ \\
\hline & & & \multicolumn{4}{|c|}{ g. $\mathrm{m}^{-2}$} & \multicolumn{2}{|c|}{$\%$} \\
\hline \multirow{2}{*}{ Strahovsky } & \multirow{2}{*}{$\begin{array}{c}\text { Cement } \\
\text { Concrete }\end{array}$} & decreasing & 1449.9 & 261.5 & 1711.4 & 6.69 & 15.3 & 2.56 \\
\hline & & increasing & 247.6 & 74.1 & 321.7 & 0.91 & 23.0 & 1.23 \\
\hline \multirow{2}{*}{ Mrazovka } & \multirow{2}{*}{$\begin{array}{l}\text { Asphalt } \\
\text { Concrete }\end{array}$} & decreasing & 946.6 & 188.5 & 1135.2 & 5.88 & 16.6 & 3.12 \\
\hline & & increasing & 91.2 & 39.7 & 130.9 & 1.26 & 30.3 & 3.17 \\
\hline
\end{tabular}

Higher amount of dust fall was determined in the tunnel with cement concrete (CC) pavement that indicates more intensive abrasion of this type of pavement (Table 3). This is in accordance with the previous results from PM measurements next to the roads with different pavement types. However, higher amount of dust was measured in the downward-sloping tube of both tunnels. The share of inorganic content in dust fall in the downward sloping tube was about $84 \%$ whereas in the upward sloping tube of the tunnels it was about $60 \%$ of dust fall. Also the share of PAH on organic dust fall was smaller. The reason could be a higher PM production because of brake shoe lining wear during more intensive braking.

Selected elements contents were also determined in dust fall in both tunnels. There was found no statistically significant correlation between the tunnels or more precisely between the pavement types (see Fig. 5). The only correlation was determined for the content of Ba between the decreasing and increasing tubes of both tunnels namely its concentration was higher in the downward sloping tube. This element was mostly originated due to brake lining abrasion so the interpretation of this fact could be more intensive vehicle braking.

\subsection{Noise results}

During TUZA research activities of the SPENS project SPB measurements were carried out according to the ISO 11819-1 standard on 4 measuring positions (Fig. 6) and results are presented in Figs. 7 and 8.
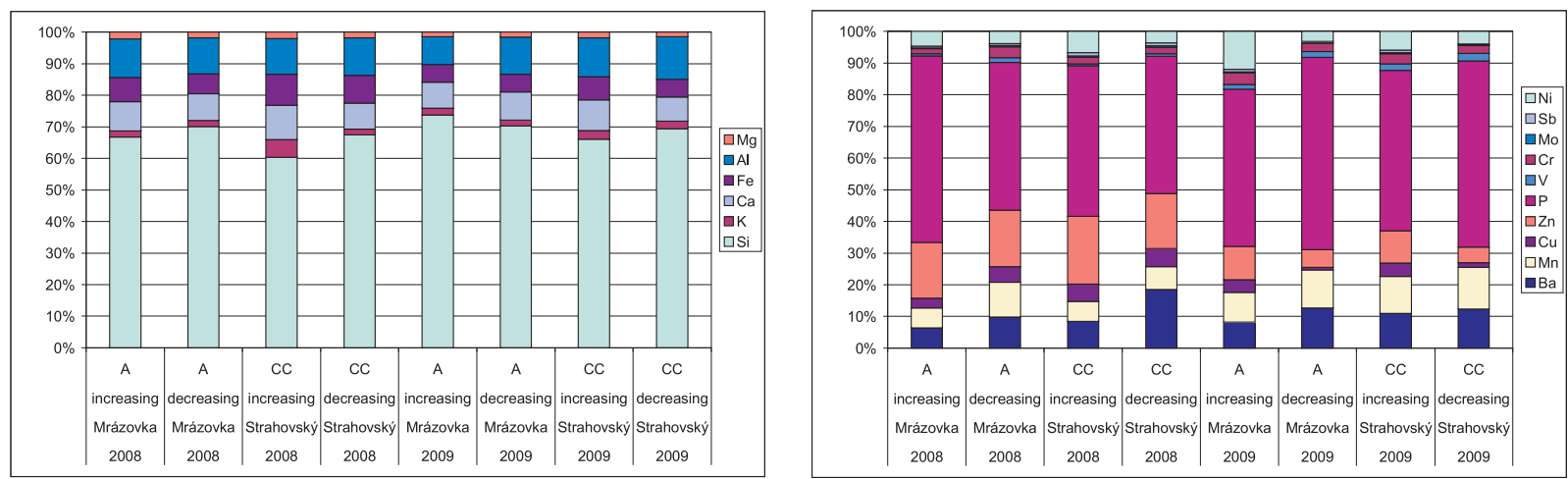

Fig. 5 Comparison of macro element concentrations on the left graph and comparison micro element concentrations on the right graph

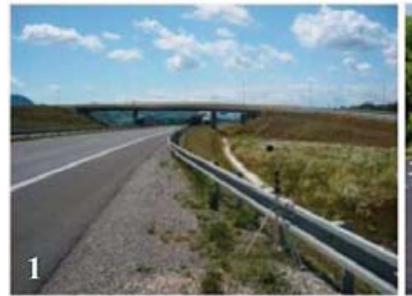

Measuring position 1

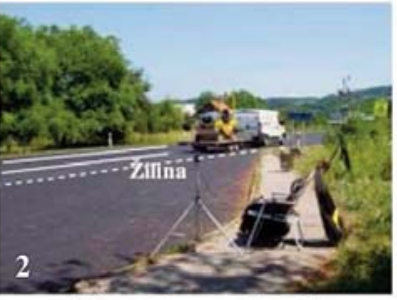

Measuring position 2

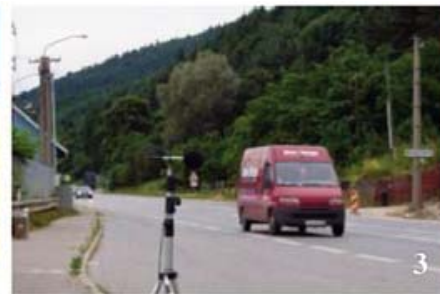

Measuring position 3

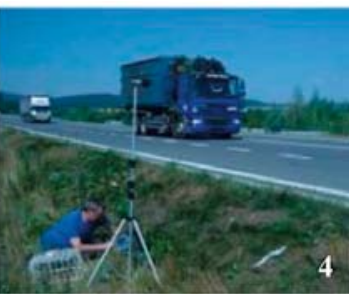

Measuring position 4

Fig. 6 Views of the measuring position 1 - 4 around Zilina 

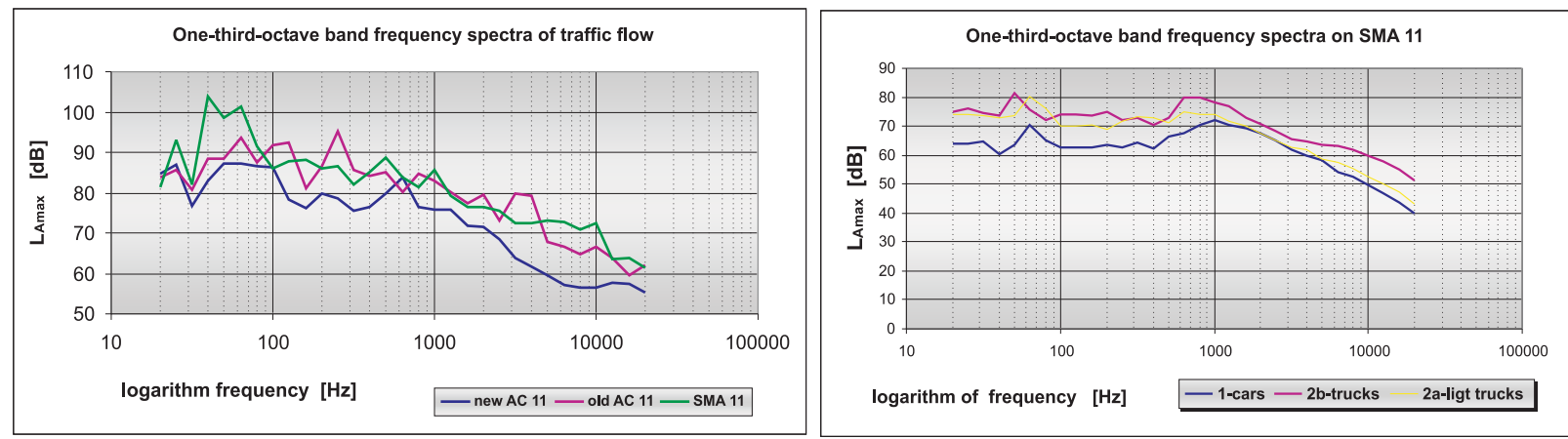

Fig. 7 Examples of one-third-octave band frequency spectra - normally evaluated L A(max), 15min of traffic flow

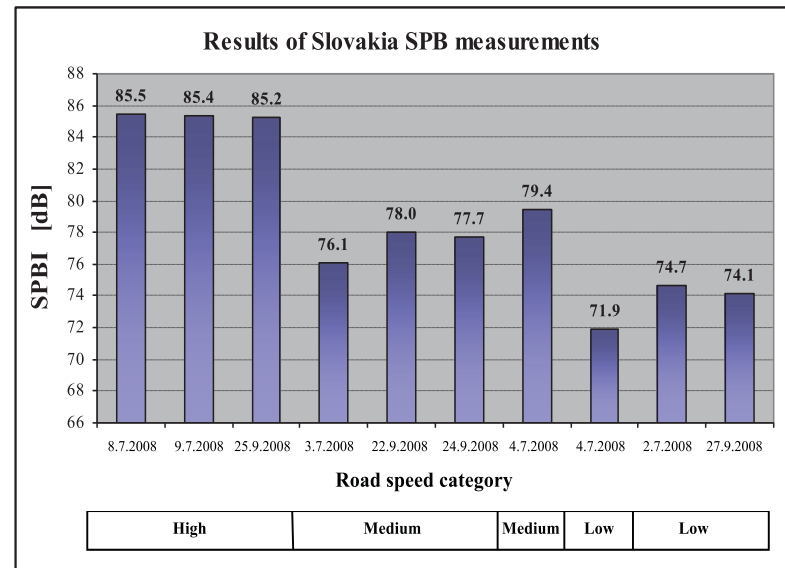

\begin{tabular}{|c|c|}
\hline $\begin{array}{l}\text { Position } 1 \text { - highway D1, Horny Hricov } \\
\text { - SMA } 11 \text { PmB (polymer modified } \\
\text { bitumen) } \\
\text { - pavement } 2 \text { years old }\end{array}$ & $\begin{array}{c}\text { Position } 3 \text { - road } 1^{\text {st }} \text { class, Dolny Hricov } \\
-\mathrm{AC}_{\mathrm{o}} 11 \\
-15 \text { years old }\end{array}$ \\
\hline 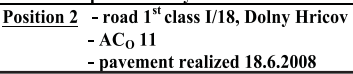 & $\begin{array}{c}\text { Position } 4 \text { - road } 3^{\text {st }} \text { class, Bytca } \\
\text { - SMA } 11 \\
\text { - } 4 \text { years old }\end{array}$ \\
\hline
\end{tabular}

Fig. 8 Results of Slovakia SPB measurements obtained during TUZA research activities of SPENS

\section{Conclusions}

PM measurements performed in Slovakia on localities with different road pavements, asphalt concrete and stone matrix asphalt indicate a higher production of coarse PM fraction due to abrasion of asphalt concrete pavement. These particles contain more $\mathrm{Ca}, \mathrm{Mg}$ and $\mathrm{Fe}$ from abrasion of pavement but they also contain $\mathrm{Zn}$ originated probably due to abrasion of tyres.
Dust fall measurements in road tunnels in the Czech Republic indicate a higher production of particles due to abrasion of cement concrete pavement comparing with dust production in the road tunnel with asphalt concrete pavement. The share of inorganic content in dust fall in the downward sloping tube was about $84 \%$ whereas in the upward sloping tube of the tunnels it was about $60 \%$ of dust fall. This indicates higher PM production due to brake shoe lining wear during more intensive braking and is supported by a higher content of $\mathrm{Ba}$ in this tunnel tube.

The differences in SPBI of old and new AC for a medium road speed category were about $3 \mathrm{~dB}$ and the differences in SPBI of SMA (4 year old) and new AC for a low road speed category were about $2.5 \mathrm{~dB}$. The average reduction of noise pollution in external environment in the pavement vicinity at level $3 \mathrm{~dB}$ corresponds with the decrease of traffic intensities from 1000 to $500 \mathrm{veh} . / \mathrm{hr}$. Slovakian experts recommended that before and after larger pavement reconstructions it is greatly convenient to perform measurements of the influence of road surfaces on traffic noise by means of the SPB method. The reference temperature needs to be implemented in relevant laws, standards and guidelines and results of traffic noise monitoring should be corrected to the reference temperature.

According to the authors the presented facts can help to fill the next premise for an environmental correct design and maintenance of pavements. The pavements have to be designed, constructed and maintained in such a way as to meet the requirement the environmental protection, such as noise reduction at wheel rolling [15].

\section{Acknowledgements}

This work was supported by European Commission under FP6 project SPENS (Sustainable Pavements for European New Member States), contract No. 031467.

\section{References}

[1] KRZYZANOWSKY, M., KUNA-DIBBERT, B., SCHNEIDER, J. (Eds.): Health Effects of Transport-related Air Pollution. WHO Europe, 190 p., 2005, ISBN 92-890-1373-7. 
[2] KUNZLI, N., KAISER, R., MEDINA, S. et al: Public-health Impact of Outdoor and Traffic-related Air Pollution: a European Assessment. The Lancet 356, p. 795-801, 2000.

[3] HUZLIK, J., LICBINSKY, R., DURCANSKA, D.: Polychlorinated Dibenzodioxins and Dibenzofurans Emmisions from Transportation. Communications - Scientific Letters of the University of Zilina, vol. 13, No. 3, pp. 41-47, 2011, ISSN 1335-4205.

[4] US EPA: Air Quality Criteria for Particulate Matter, vol. 1, 900 p., 2004.

[5] US EPA: Air Quality Criteria for Particulate Matter, vol. 2, 1148 p., 2004.

[6] BRAATEN, D. A., PAW, U. K. T., SHAW, R. H.: Particle Resuspension in a Turbulent Boundary Layer Observed and Modelled. J. of Aerosol Science 21, p. 613-628, 1990.

[7] DAVIS, A. P.; SHOKOUHIAN, M.; NI, S. B.: Loading Estimates of Lead, Copper, Cadmium, and Zinc in Urban Runoff from Specific Sources. Chemosphere 44, pp. 997-1009, 2001.

[8] PAKKANEN, T. A., KERMINEN, V. M., LOUKKOLA, K. et al.: Size Distribution of Mass and Chemical Components in Streetlevel and Rooftop PM1.0 Particles in Helsinki. Atmospheric Environment 37, pp. 1673-1690, 2003.

[9] LOUGH, G. C., SCHAUER, J. J., PARK, J. S. et al.: Emissions of Metals Associated with Motor Vehicle Roadways. Environmental Science and Technology 39, p. 826-836, 2005.

[10] DURCANSKA, D.: Analysis of Particulate Matter Composition. Communications - Scientific Letters of the University of Zilina, vol. 12, No. 3A, p. 17-22, 2010, ISSN 1335-4205.

[11] SNILSBERG, B., MYRAN, T. UTHUS, N. et al.: Characterization of Road Dust in Symposium Proceedings. The $8^{\text {th }}$ Intern. symposium on Cold Region Development, ISCORD. Trondheim : Tampere, 2007.

[12] YLI-TUOMI, T., AARNIO, P., PIRJOLA, L. et al.: Emissions of Fine Particles, NOx, and CO from On-road Vehicles in Finland. Atmospheric Environment, 39, p. 6696-6706, 2005.

[13] ZEREINI, F., SKERSTUPP, B., ALT, F. et al.: Geochemical Behaviour of Platinum-Group Elements (PGE) in Particulate Emissions by Automobile Exhaust Catalysts: Experimental Results and Environmental Investigations. Science of the Total Environment 206, p. 137-146, 1997.

[14] STN EN ISO 11819-1 Acoustics. Measurement of the Influence of Road Surfaces on Traffic Noise. Part 1: Statistical Pass-By method (ISO 11819-1:1997).

[15] COREJ, J., DECKY, M.: Pavements from the Point of View of Future Requirement of Road Transport. Communications - Scientific Letters of the University of Zilina, No. 1, p. 57-64, ISSN 1335-4205, 1999. 